\title{
Effect of Yoga (Pranayama) in Improving Pulmonary Function Tests In Pediatric Age Group: a One Year Prospective Study
}

\author{
A. R. Somashekar, B. C. Arun, Arpitha Panduranga, Dharmapuri Vidyasagar, Shivaraj Nallur \\ Somanna, and \\ D. Ahish
}

\begin{abstract}
Aim: The aim of the study is to find out the effect of pranayama in improving the values of pulmonary function tests, in school going children (of adolescent age group between 12 years to 15 years) having mild to moderate asthma and also not being on any long term medication for the same.

Method: After taking a written informed consent from the school teacher in charge, the parents and the children group from a government high school in Bengaluru, the screening of the children for asthma was done. Initial pulmonary function tests were done after inhaling a bronchodilator for the diagnosis of mild and moderate asthma. The diagnosed children were not put on any long term medication. They were educated about pranayama and were also taught the methodology of performing pranayama and other yoga asanas. They were made to perform pranayama every day for 20-30 minutes, for a period of 1 year (during June 2017 - June 2018) under the teacher's guidance and during this period they were examined periodically(every 3 months) for the improvement in their pulmonary function tests.

Results: FEV\% deteriorated in 16 children in the second visit and 20 children in the last visit. This could be explained by the disproportionate increase of FVC compared to FEV1.FEV\% improved better than FVC in $40 \%$ (20) of the children while the rest $60 \%$ (29) children's improvement in FVC was better than FEV\%. In the final visit around 11 children had no change in the PEFR values, which was significantly high when other lung functions were considered.

Conclusion: FEV1 has increased from first visit to fourth visit, but at each visit the increase was not significant. This suggests the beneficial effect of pranayama in improving FEV1 when it is practised regularly for prolonged duration. Thus our prospective study confirms that Pranayama could be one of the better alternative therapies that should be considered in adolescent asthma.
\end{abstract}

Index Terms - Asthma; Adolescent age group; Pranayama ; Pulmonary function test.

\section{INTRODUCTION}

Asthma is a chronic inflammatory disorder of the airways characterized by an obstruction of airflow, which may be completely or partially reversed with or without specific therapy. Asthma in pediatric population is the most prevalent chronic disorder. Approximately 1 in every 6 children suffers

Published on July 29, 2020.

A. R. Somashekar, Ramaiah Medical College and Teaching Hospital, India.

(corresponding e-mail: s_arshekar2002@yahoo.com)

B. C. Arun, Ramaiah Medical College and Teaching Hospital, India. India.

Arpitha Panduranga, Ramaiah Medical College and Teaching Hospital, from some chronic respiratory disorder.

Breathing is a normal part of our life, though we fail to pay attention to it. It is an autonomic function of the body that we perform even without concentrating on it. Pranayama teaches us the proper way to breathe. With yoga breathing, we increase the capacity of our lungs, bringing more oxygen supply to the body to function well.

Yoga breathing, or Pranayama, is the science of breath control. It consists of a series of exercises especially intended to meet the body's needs and keep it in vibrant health. Pranayama comes from the following words:

Prana - "life force" or "life energy"

Yama - "discipline" or "control"

Ayama - "expansion", "non-restraint", or "extension"

There are the four stages of Pranayama - Arambha, Ghata, Parichay \& Nispatti.

\section{A. Need for the study}

Asthma is stimulated by a multitude of factors including inhalation of allergens, food, exercise, respiratory infections, environmental irritants, dry or cold air and intense emotions. Apart from pharmacological management the psychic component of asthma is dealt with general measures like relaxation techniques, counseling and removal of the patients from the harmful environment [3]. Hypnosis and yoga (pranayama) are getting increasingly recognized as better treatment for asthma.

Asana (passive stretching of muscles) and pranayama (voluntary regulation of breathing) affects the body in several ways. Asana enhances the muscles fitness [6]-[8], [9]-[14] and decreases the muscle tension 15. Decrease in muscle tension reduces the level of arousal and physiological reactivity to stress [16], [17].

\section{B. Objectives of the study}

To find out the effect of pranayama on mild to moderate asthma in school going children of adolescent age group between 12 years to 15 years.

\section{MATERIALS AND METHODS}

The study was aimed to find the effect of Pranayama in

Dharmapuri Vidyasagar, Ramaiah Medical College and Teaching Hospital, India.

Shivaraj Nallur Somanna, Ramaiah Medical College and Teaching Hospital, India.

D. Ahish, Ramaiah Medical College and Teaching Hospital, India. 
Pediatric Asthma.

Method: During June 2017 - June 2018, on screening 900 children in $12-15$ years age group from a government high school in Bengaluru with questionnaire related to symptoms of asthma, physical examination and pulmonary function tests, 49 children were detected to be asthmatic. Pulmonary function tests were done using both peak flow meter and spirometry. Diagnosis of mild asthma was made as per GINA guidelines FEV1/FVC <85\% and FEV1 $>70 \%$ and increase in FEV1 of $>12 \%$ after inhaling a bronchodilator. None of the children were on any long term medications. A written informed consent was taken from the school teacher in charge, the parents and the children. Asana and Pranayama were taught to the children under the supervision of a yoga expert.

Few pranayama and yoga postures that were practised in the study are:

Nadi Shodhan pranayama (Alternate Nostril Breathing technique)

Kapal Bhati pranayama (Skull Shining Breathing technique)

Ardha Matsyendrasana (Sitting Half Spinal Twist)

Pavanamuktasana (Wind Relieving Pose)

Setu Bandhasana (Bridge Pose)

Bhujangasana (Cobra Pose)

Adho Mukha Svanasana (Downward-Facing Dog Pose)

Badhakonasana (Butterfly Pose)

Poorvottanasana (Upward Plank Pose)

Shavasana (Corpse Pose)

Pranayama was practised by the participants 20-30 minutes a day for 9 months under the supervision of a teacher. A diary card was maintained by each student regarding symptoms, attendance for the pranayama participation and PFTs. Each participant was evaluated with history, physical examination and PFT every 3 months once using ACT tool during the study period. The subsequent improvement was computed.

\section{A. Inclusion Criteria}

Children between 12 - 15 years with mild asthma (FEV1/FVC $<85 \%$ and $\%$ predicted FEV1 $>70 \%$ ).

\section{B. Exclusion Criteria}

Asthmatic children who were on inhalers and long term steroids.

Children with moderate to severe asthma (FEV $1<70 \%$ of the predicted value).

Children with other acute or chronic respiratory or associated systemic illnesses.

\section{RESUlTS}

The number of people and their mean percentage of improvement in lung function during each examination after initial screening were documented. The predicted PEFR is expressed as a percentage of the expected value.

A significant positive correlation was observed between BMI and PEFR, FVC, FEV1 with a 'p' value of $<0.001$. An insignificant negative correlation was observed between BMI and FEV\% with a 'p' value of $>0.001$.

FEV\% deteriorated in 16 children in the second visit and 20 children in the last visit. This could be explained by the disproportionate increase of FVC compared to FEV1. FEV\% improved better than FVC in $40 \%$ of the children while the rest $60 \%$ improvement in FVC was better than FEV\%. In the final visit around 11 children had no change in the PEFR values, which was significantly high when other lung functions were considered.

\begin{tabular}{|c|c|c|c|c|c|c|c|c|c|c|}
\hline Variable & First & Second & Third & Fourth & P -value & $\begin{array}{c}\text { First Vs } \\
\text { Second }\end{array}$ & $\begin{array}{c}\text { Second Vs } \\
\text { Third }\end{array}$ & $\begin{array}{c}\text { Third Vs } \\
\text { Fourth }\end{array}$ & $\begin{array}{c}\text { First Vs } \\
\text { Fourth }\end{array}$ & $\begin{array}{c}\text { Trend } \\
\text { FEV 1 }\end{array}$ \\
\hline FVC & $1.09 \pm 0.38$ & $1.21 \pm 0.42$ & $1.25 \pm 0.57$ & $1.35 \pm 0.61$ & 0.002 & 0.251 & 1.00 & 0.764 & 0.004 & 0.021 \\
\hline $\begin{array}{c}\text { FEV1/F } \\
\text { VC }\end{array}$ & $68.9 \pm 7.2$ & $73.8 \pm 6.9$ & $77.7 \pm 8.1$ & $82.6 \pm 14.4$ & $<0.001$ & $<0.001$ & 0.001 & 0.024 & $<0.001$ & $<0.001$ \\
\hline
\end{tabular}

FEV1 has increased from first visit to fourth visit and found to be statistically significant $p=0.004$, but at each visit the increase was not statically significant. Suggesting the beneficial effect of pranayama in improving FEV1 when it is practised regularly for prolonged duration.

The change in the FVC was found to be statistically not significant.

The increase in FEV1/FVC from the first visit to fourth visit was statistically significant $p<0.001$ and also at each visit the change from the previous visit was statistically significant. The constant increase in FEV1 during each visit in relation to a relatively constant $\mathrm{FVC}$ is reflected in statistically significant increase in FEV1/FVC ratio.

\section{DISCUSSION}

Asthma as defined by GINA guidelines is a chronic airway inflammatory disease which presents with heterogeneous features such as wheezing, shortness of breath, chest tightness, and cough that vary over time in their occurrence, frequency and intensity. These symptoms are associated with variable expiratory airflow. Asthma is one of the common chronic diseases of childhood. The prevalence of asthma is significantly increasing worldwide which is attributable to multiple environmental changes. There are multiple triggering factors of asthma like dust mite, respiratory viruses, tobacco smoke, air pollutants, drugs, cold air, physical exercise, emotional stress etc. The clinical manifestations of asthma range from mild intermittent symptoms of cough, wheezing to severe exacerbations that can be potentially life threatening. 
Treatment of asthma includes reliever medication like SABA and preventer medication like ICS. The treatment cost for prolonged use of ICS, spacer and medical care including outpatient as well as inpatient visits is a burden to the family. It also requires a basic knowledge of the disease and skills to administer the medications. Poor compliance with long term use of ICS is one of the major limitations in asthma management. long term use of ICS may have drug-related adverse effects, including mild acute symptoms such as dysphonia and thrush and severe adverse effects like hypothalamic-pituitary-adrenal axis suppression, reduction in growth velocity, osteoporosis, diabetes, and respiratory infections [25]. Another important aspect of asthma treatment is control of exposure to triggers, but it is practically difficult to identify and avoid the triggers in an individual patient. These factors may limit the use of ICS and look for alternate effective and safe treatment modality.

Yoga that includes breathing exercises is found to have a positive effect in asthma treatment as shown in many previous studies. The effect of yoga on psycho-neuroimmunology is thought to be the mechanism by which yoga brings improvement in asthma patients [26]. Psychological and emotional stress itself can trigger asthma exacerbation by inducing mast cell degranulation via Corticotropin releasing hormone [27]. Yoga improves emotional function and in turn reduces mast cell activation. Yoga also reduces airway inflammation through various unknown mechanisms, which has been in animal models of asthma [28]. It is also a safe and cost effective intervention in asthmatic children.

Pulmonary function test is an important tool in evaluating children with asthma. It is used for diagnosis, to assess the degree of impairment and impact of therapies. Mild asthma is defined as FEV1/FVC $<85 \%$ and FEV1 $>70 \%$ with increase in PEF $>12 \%$ after inhalation of a bronchodilator.

In our study, 49 out of 900 school children between 12-15 years were diagnosed to have mild asthma according to GINA guidelines by using PFT. They were not on long term medications during the study duration. All children diagnosed with mild to moderate asthma were trained with Asana and Pranayama by a yoga expert and pranayama was practiced by them 20-30 minutes a day for 9 months under the supervision of a teacher. participants were periodically evaluated during the study period with history of symptoms, physical examination and PFT during the study period. Study reveals that introduction and practice of pranayama (effective breathing) in mild to moderate asthmatics improves the systemic score.

Our results were consistent and well supported with the studies of Bhagwat et al, Satyaprabha et al, Gore MM et al and Behera D and Jindal SK et al. Improved lung functions function was proved in a few more studies. Rise in vital capacity (VC) and peak expiratory flow rates after the yoga therapy is indicative of reduced airway resistance.

The limitations of our study could be that - long term follow up of the children enrolled in the study is difficult, there can be confounding factors like avoidance of allergens and other triggering factors as a result of awareness regarding asthma, which may influence the contribution of yoga in the study. Absence of a control group can be a limitation.

\section{CONCLUSION}

Thus, our prospective study confirms that Pranayama could be one of the better alternative therapies that should be considered in adolescent asthma. The health education given could be an important reason for the decrease in the acute exacerbations, but the relative contribution of Pranayama and health education to the improvement in the asthmatic symptoms and lung functions are unknown.

\section{REFERENCES}

[1] Tecklin, BS: Therapy for children with chronic lung disease: Volume 61/No 12; December 1981

[2] Gordis L: Bronchial Asthma. In Gordis L(ed): Epidemiology of chronic lung disease in children. Baltimore, MD, John Hopkins University Press, !973, pp4 - 52 .

[3] Behera D \& Jindal SK. Effect of yogic exercises on Bronchial Asthma: Lung India (1990) 8, No 4, p.187- 189.

[4] A report to the Research Committee of Brit TB Assoc. Hypnosis for asthma; A controlled clinical trial. Brit Med J., 1968, 4: 71 - 76.

[5] Gharote ML. Psychophysiological study of the effect of short - term yogic training on the adolescent high school boys. Yoga Mimamsa. 1971 ; $14(1 \& 2) 92-9$.

[6] Moses R, Effect of yoga on flexibility and respiratory measures of vital capacity and breath holding time. D.Ed. Dissertation. 1972; University of Oregaon - USA.

[7] Salagar DC, Bisen YS, Jinturkar MJ. Effect of Padmasana - a yogic exercise on muscular efficiency. Ind.J.Med.Res.1975; $768-772$.

[8] Karambelkar PV, Bhole MVand Gharote ML. Muscle activity in some asanas. A pilot study. Yogic Mimamsa 1969; 12(1) 1 - 13.

[9] Markey, J, Immunopharmacology of Asthma. Immunol Today 14:3179, 1993.

[10] Bhole MV, effect of yogic treatment on various lung functions of asthma patients - a pilot study. Yoga Mimamsa. 1982:20(4) 43 - 50.

[11] Gore MM. Effect of yogic treatment on some pulmonary functions in asthmatics. Yoga Mimamsa, 1982:20(4) $51-8$.

[12] Kulvayanada Swami. Pranayama. Publ. Kaivalyadhama, Lonavla. 1966.

[13] Goyeche J: Asthma: The yoga perspective. Part 2: Yoga therapy in the treatment of asthma. J Asthma 19: 189 - 201, 1982 Abstract.

[14] Jain SC, Rai L, Valecha Aet al: Effect of yoga training on exercise tolerance in adolescents with childhood asthma. J Asthma 28: 437 - 442, 1991 Abstract.

[15] Singh V, Wisniewski A, Britton J, Tattersfield A. Effect of yoga breathing exercises (pranayama) on airway reactivity in subjects with asthma Lancet 1990 Jun 9;335 (8702): 1381 - 3.

[16] Vedanthan PK, Kesavalu LN, Murthy KC, Duvall K, Hall MJ, Baker S, Nagarathna S. Clinical study of yoga techniques in university students with asthma: A controlled study. Allergy Asthma Proc 1998 Jan - Feb; 19(1):3-9.

[17] Singh V, Wisniewski A, Britton J, et al. Effect of yoga breathing exercises (pranayama) on airway reactivity in subjects with asthma. Lancet 1990; 335: 1381 - 3-Medicine.

[18] Satyaprabha TN, Murthy H, Murthy BT. Efficacy of naturopathy and yoga in bronchial asthma - a self controlled matched scientific study. Indian J Physiol Pharmacol 2001 Jan; 45(1): $80-6$.

[19] Bhole MV, effect of yogic treatment on various lung functions of asthma patients - a pilot study. Yoga Mimamsa, 1982:20(4) 43 - 50.

[20] Gore MM. Effect of Yogic treatment on some pulmonary functions in asthmatics. Yoga Mimamsa, 1982:20(4) $51-8$.

[21] Murthy KJR, Sahay BK, Staram Raju P, Madhavi Sunita, Ramanand Yogi, Venkata Reddy M, Annapurna V, VijayalakshmiParshad and Eshwara Reddy M. Effect of Pranayama on Asthma. Lung India. 1984, 2:187-191.

[22] Bhole MV \& Karamblekar PV. Effect of yoga training on vital capacity and breath holding time. Yoga Mimamsa, 1971: 14(3 \& 4): $19-24$.

[23] Gore MM and Gharote ML. Effect of Yogic treatment on peak flow rate. Yoga Mimamsa, 1981: 14(1 \& 2): $100-4$

[24] Bhagwat JN, Soman AM and Bhole MV. Yogic treatment of bronchial asthma - a medical report. Yoga Mimamsa, 1981:20(3): 1-2

[25] Heffler, E., Madeira, L. N. G., Ferrando, M., Puggioni, F., Racca, F., Malvezzi, L., ... \& Canonica, G. W. (2018). Inhaled corticosteroids safety and adverse effects in patients with asthma. The Journal of Allergy and Clinical Immunology: In Practice, 6(3), 776781.Satyaprabha TN, Murthy H, Murthy BT. Efficacy of naturopathy and yoga in bronchialasthma - a self controlled matched scientific study. Indian J Physiol Pharmacol 2001 Jan; 45(1): $80-6$. 
[26] Vempati, R., Bijlani, R. L., \& Deepak, K. K. (2009). The efficacy of a comprehensive lifestyle modification programme based on yoga in the management of bronchial asthma: a randomized controlled trial. BMC pulmonary medicine, $9(1), 37$.

[27] Theoharides, T. C., Spanos, C. O. N. S. T. A. N. T. I. N. E., Pang, X. I. N. Z. H. U., Alferes, L. I. S. A., Ligris, K. O. N. S. T. A. N. T. I. N. O. S., Letourneau, R. I. C. H. A. R. D., ... \& Chrousos, G. P. (1995). Stressinduced intracranial mast cell degranulation: a corticotropin-releasing hormone-mediated effect. Endocrinology, 136(12), 5745-5750.

[28] Luks, V., Burkett, A., Turner, L., \& Pakhale, S. (2013). Effect of physical training on airway inflammation in animal models of asthma: a systematic review. BMC pulmonary medicine, 13(1), 24.

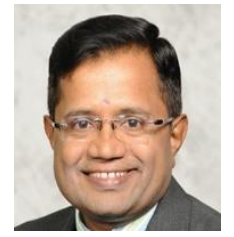

Dr.Somashekar.A. R. - Professor \& HOD of Pediatrics, Ramaiah Medical College, Paediatric pulmonologist and Adolescent care specialist, Organizing Secretary, 19th National Conference of Adolesent Health Academy IAP, Organizing Secretary- COMHAD 2019, Chairperson, Bangalore Adolescent Health academy 2018, EB Central IAP- 2015 \& 2017.

EB.Central IAP Respiratory chapter

Organizing Secretary Pedicon 2017

Secretary AHA: 2016-2017

Joint Secretary IAP, Bangalore-2016

President IAP State Respiratory Chapter. 2015-2016

Treasurer: IAP Allergy chapter 2015

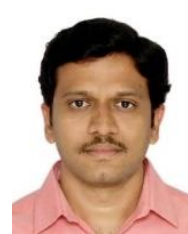

Arun B. C. was born on 18-11-1988 in Chikkamagalur, Karnataka, India.

He did his Diploma in Child Health from Bangalore Medical College and Research Center, Bangalore and DNB Paediatrics from Manipal Hospitals, Old Airport Road, Bengaluru, Karnataka.

Dr. Arun B. C. works as Senior Resident, Department Of Pediatrics, M S Ramaiah Medical College \&

Teaching Hospital.

His Dissertation Topic was- Clinical, Laboratory and Echocardiographic profile of children with Kawasaki disease and factors influencing development and outcome of coronary artery abnormalities.

His other clinical skills includes PALS (Paediatric Advanced Life Support)

NRP (Neonatal Resuscitation Protocol).

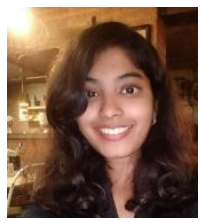

Arpitha Panduranga was brn in Bangalore on 25/12/1990. She did her MD Paediatrics from Ramaiah Medical College Bangalore, Karnataka, India.

Dr. Arpitha Panduranga worked as a Senior Resident at Department Of Pediatrics, M S Ramaiah Medical College \& Teaching Hospital.

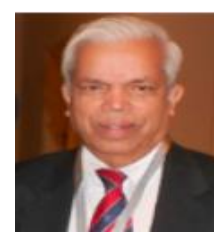

Dharmapuri Vidyasagar, Professor Emeritus Pediatrics, Division of neonatology, University of Illinois at Chicago, Chicago. ILL 60523, USA. Associate Professor, Department of Community Medicine, M S Ramaiah Medical College \& Training Hospital.

Dr. Dharmapuri Vidyasagar, MD is a neonatal medicine specialist in Chicago, IL and has been practicing for 55 years. He graduated from Osmania Medical College, NTR University Of Health Sciences in 1961 and specializes in neonatal medicine and perinatal medicine

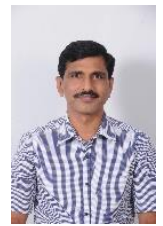

Shivaraj Nallur Somanna - Assistant Professor, Department of Community Medicine, Ramaiah Medical College \& Training Hospital.

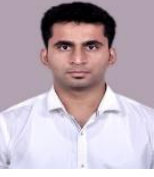

Ahish D. was born in Bangalore on 28/04/1995

Ahish D has obtained his MBBS degree from the prestigious Rajiv Gandhi University of Health Sciences. He has worked as a Junior Resident in the Department of Paediatrics, Ramaiah Medical College \& Teaching Hospital.

Dr.Ahish D has also published a research article for ICMR Short Term Studentship during his undergraduate days. 